\title{
Optimasi Penggunaan Android Sebagai Peluang Usaha Di Masa Pandemik COVID'19
}

\author{
Seta Samsiana ${ }^{1}$, Rahmadya Trias Handayanto ${ }^{1}$, Anita Setyowati Srie Gunarti ${ }^{1}$ \\ Irwan Raharja ${ }^{2}$, Fata Nidaul Khasanah ${ }^{3}$, Herlawati ${ }^{3,}{ }^{*}$, Maimunah ${ }^{4}$, Benrahman ${ }^{5}$ \\ ${ }^{1}$ Fakultas Teknik, Universitas Islam 45; Jl. Cut Meutia No 83, Bekasi, Jawa Barat, Indonesia; e- \\ mail: set4sam@gmail.com, rahmadya.trias@gmail.com, anita ft@unismabekasi.ac.id \\ ${ }^{2}$ Fakultas Teknologi Informasi, Universitas Bina Sarana Informatika; Jl. Banten No. 1, \\ Karangpawitan, Karawang Barat, Jawa Barat, Indonesia; e-mail: irwan.ira@bsi.ac.id \\ ${ }^{3}$ Fakultas Teknik, Universitas Bhayangkara Jakarta Raya; Jl. Raya Perjuangan, Marga Mulya, \\ Bekasi Utara, Jawa Barat 17121. Telp: 021-88955882, 889955883;e-mail: \\ fatanidaul@gmail.com; herlawati@ubharajaya.ac.id \\ ${ }^{4}$ Fakultas Teknik, Universitas Muhamadiyah Magelang; Jl. Mayjend Bambang Soegeng KM 5 \\ Mertoyudan, Magelang, Jawa Tengah, Indonesia, e-mail: maimunah@ummgl.ac.id \\ ${ }^{5}$ Fakultas Teknologi Komunikasi Dan Informatika, Universitas Nasional; Jl. Sawo Manila, \\ RT.14/RW.3, Ps. Minggu, Kec. Ps. Minggu, Kota Jakarta Selatan, Daerah Khusus Ibukota \\ Jakarta 12520, e-mail: benrahman@civitas.unas.ac.id \\ * Korespondensi: e-mail: herlawati@ubharajaya.ac.id
}

\begin{abstract}
Some community service activities have been done as a tangible form in building a resilient community in the current Covid '19 pandemic situation. Indonesia at the moment, from the various sectors of life, experienced the bad impact caused by this pandemic, especially in the economic sector. The current community service activity has three objectives: general, specific and sustainable objectives. It has been carried out to accelerate the growth of entrepreneurialskill and independent communities to fight against covid'19 disaster. Housewives, in particular, the committee members of Islamic elementary school (SDIT) Prestasi Cendikia in Bekasi became our target community. The implementation process was as follows. 1) Participant registration through the Webinar. 2) Implementation of the activity through an online meeting with Google Meet, which was divided into two sessions, i.e. the first session of theoretical material such as Android functions, means of promotion, and managing the risk of failure; the importance of mastery of Android as a social medium of sales was explained. In addition, some technical application sessions were demonstrated directly in making the sales on the android app, i.e. shoope, selly and canva. 3) The evaluation where each participant filled a response about the implementation of this community service both training and workshop. The results of the questioner were presented through menti.com site that can be seen directly the values or graphs based on the participants' responses. The results showed that the participants demonstrated their creativity and were able to utilize Android as well as the social media to sell products (services and goods).
\end{abstract}

Keywords: Community Service, Android, SDIT Prestasi Cendikia.

\begin{abstract}
Abstrak
Kegiatan pengabdian kepada masyarakat ini muncul sebagai wujud nyata membangun masyarakat tangguh di era pandemik Covid'19. Dimana Indonesia saat ini, dari berbagi sektor kehidupan mengalami kepurukan dihantam habis dampak pandemik, terlebih pada sektor ekonomi. Kegiatan ini mempunyai tiga tujuan, tujuan secara umum, khusus dan berkepanjangan. Kegiatan ini dilakukan untuk percepatan proses pertumbuhan kewirausahaan masyarakat mandiri dalam suasana Covid'19. Ibu-ibu rumah tangga khususnya anggota komite sekolah SDIT Prestasi Cendikia Bekasi menjadi masyarakat bidikan pengabdian kami. Metode
\end{abstract}


pelaksanaan diawali dengan (1) Registrasi peserta melalui google form, Tahap (2) Pelaksanaan kegiatan melalui google meet, dengan materi seperti fungsi Android, sarana promosi, managemen dan resiko kegagalan, serta penjelaskan akan pentingnya penguasaan Android sebagai meda social penjualan. Tahap (3) Evaluasi: setiap peserta mengisi respon atau tanggapan terhadap pelaksanaan workshop pengabdian masyarakat ini. Hasil dari kuesioner melalui menti.com akan terlihat langsung nilai ataupun grafik tanggapan peserta pelatihan. Respon yang diperoleh kegiatan workshop bagus dan perlu dilanjutkan untuk masa-masa berikutnya. Hasil pelatihan ini peserta mampu melatih kreatifitas, membangun semangat memulai bisnis online dengan memanfaatkan penggunaan Android sebagai media sosial penjualan produk-produk baik jasa maupun barang.

Kata Kunci: Pengabdian Masyarakat, Android, SDIT Prestasi Cendikia.

\section{Pendahuluan}

Pandemi Covid'19 yang terjadi baru-baru ini telah menciptakan seruan kepada pendidikan tinggi untuk mengubah praktik pengajaran, pembelajaran dan pengabdian mereka dari interaksi tatap muka langsung ke pembelajaran daring berbasis internet. Pengabdian kepada masyarakat dilakukan untuk menerapkan ilmu pengetahuan dan mencerdaskan masyarakat secara langsung yang terprogram pada kegiatan dosen. Dari 265 juta total penduduk Indonesia, 130 jutanya adalah pengguna aktif media sosial. 177 juta pengguna handphone di Indonesia, 120 juta aktif di media social. Saat ini perkembangan teknologi data digital untuk pemasaran dan penjualan berkembang dengan pesatnya. Dengan adanya internet proses pemasaran dan penjualan di media sosial Android dapat dilakukan kapan saja tanpa terikat ruang dan waktu. Turban, Lee, King, Chung (2000) menyatakan bahwa sebuah konsep yang dapat digambarkan sebagai proses jual beli barang pada internet atau sosial media, atau pertukaran produk dan jasa serta informasi melalui internet dinamakan Electronic Commerce atau yang biasa disingkat dengan e-commerce. Pemasaran produk melalui e-commerce dapat memperoleh manfaat serta keuntungan lebih karena efisien dan lebih murah serta memiliki akses tanpa batas. Ketika sebuah bisnis memiliki alamat di internet, apa yang ditampilkan dalam internet dapat diakses pengunjung dari belahan dunia manapun selama di daerah tersebut memiliki akses internet. Semakin banyak orang mengunjungi alamat internet tersebut, semakin besar pula potensi untuk memperoleh pendapatan. Aplikasi sosial media di Android membuka peluang tidak hanya bagi usaha besar, namun juga usaha kecil dan menengah untuk memasarkan dan menumbuhkan jaringan usaha di seluruh belahan dunia usaha. Pelaku usaha dituntut menjadi bagian dari komunitas global dengan memanfaatkan teknologi informasi melalui media sosial di Android. Jika mereka tidak mengikuti perkembangan teknologi informasi akan tertinggal jauh dan kalah dalam persaingan. (Suyanto, 2003).

Kegiatan pengabdian kepada masyarakat yang terprogram rutin oleh dosen adalah wajib dilakukan agar ilmu pengetahuan dan teknologi seorang dosen tidak sekedar bermanfaat di perkuliahan tetapi juga mampu menyelesaikan permasalahan di lingkungan masyarakat. Masyarakat yang menjadi sasaran kegiatan ini adalah Komite Sekolah SDIT Prestasi Cendikia yang beralamat di Jl. Kp. Gebang No.100, Karangsatria, Kec. Tambun Utara, Bekasi, Jawa Barat 17510. Komite Sekolah merupakan lembaga mandiri yang terdiri dari 
sekumpulan orangtua/wali peserta didik, komunitas sekolah, serta tokoh masyarakat yang peduli pendidikan. Komite Sekolah diatur dengan Permendikbud Nomor 75 Tahun 2016 tentang Komite Sekolah. Komite Sekolah dibentuk dengan maksud agar suatu organisasi masyarakat sekolah dapat berkomitmen dan loyalitas serta peduli terhadap peningkatan kualitas sekolah. Komite sekolah yang dibentuk dapat dikembangkan secara khas dan berakar dari budaya, demografis, ekologi, nilai kesepakatan, serta kepercayaan yang dibangun sesuai dengan potensi masyarakat setempat. Komite sekolah yang dibangun harus merupakan pengembangan kekayaan filosofis masyarakat secara kolektif. Artinya, komite sekolah mengembangkan konsep yang berorientasi kepada pengguna (client model), berbagai kewenangan (power sharing and advocacy model), dan kemitraan (partnership model) yang difokuskan pada peningkatan mutu pelayanan pendidikan.

Kegiatan pengabdian yang dilakukan berupa workshop online yang mempunyai tiga tujuan yaitu tujuan secara umum, khusus dan berkepanjangan. Awal dari kegiatan ini adalah untuk percepatan proses pertumbuhan kewirausahaan pada masyarakat, khususnya ibu-ibu rumah tangga dalam suasana pandemi Covid-19. Tujuan Secara Umum, peserta mampu membuat peluang bisnis dari penguasaan Android yang sudah dimiliki. Tujuan secara khusus, peserta mampu meningkatkan penguasaan Android dengan baik dan dapat membuat bisnis sendiri serta mampu membuat bisnis-bisnis kecil untuk membantu para sahabat/kerabat untuk berbisnis dengan menggunakan Android. Sedangkan tujuan jangka panjang peserta memiliki bisnis yang besar (e-commerce, seperti Shopee).

Beberapa kegiatan dengan tema seperti ini juga telah dipublikasikan oleh beberapa penulis diantaranya (Baskoro \& Maulidian, 2019) dengan judul Pelatihan Instagram Marketing Untuk Tenant Inkubator Bisnis Trilogi. Pelatihan Penggunaan Jejaring Sosial Instagram Dalam Memasarkan Barang Pada Ibu-lbu Pkk Di Kelurahan Rawamangun Jakarta Timur, ditulis oleh (Febrilia et al., 2017) Sementara (Purwati \& Perdanawanti, 2019) melaporkan pelaksanaan kegiatan pengabdian kepada masyarakat berupa Pelatihan Desain Menggunakan Aplikasi Canva Untuk Anggota Komunitas Ibu Profesional Banyumas Raya. (Rachman \& Ramdani, 2016) melaporkan kegiatan IBM Pelatihan Pemanfaatan E-Commerce Sebagai Media Pemasaran Global Untuk Peningkatan Penjualan Produk Kelom Geulis (Studi Kasus: Ukm Kelom Geulis Tamansari Tasikmalaya. (Rifai \& Oktaviana, 2018) menulis kegiatan pengabdian masyarakat berupa Pelatihan Aplikasi Teknis Online Marketplace Pada Sentra Umkm Banyumas "Pratistha Harsa" Untuk Pemasaran Produk Secara Online. Judul tulisan Pelatihan Pemasaran Produk Homemade Melalui Sosial Media dilaporkan oleh (Werdani et al., 2020).

\section{Metode Pelaksanaan}

Panitia kegiatan untuk mempersiapkan kegiatan workshop supaya berjalan dengan baik dan lancar, sudah mengadakan beberapa kali pertemuan online untuk membicarakan kegiatan ini. Pertemuan koordinasi ini tetap dilaksanakan secara online karena sedang masa pandemik 
Seta Samsiana, Rahmadya Trias Handayanto, Anita Setyowati Srie Gunarti, Irwan Raharja,

Fata Nidaul Khasanah, Herlawati, Maimunah, Benrahman

Covid'19, menggunakan beberapa aplikasi meeting online misalnya: zoom, buzme.in dan lainlain.

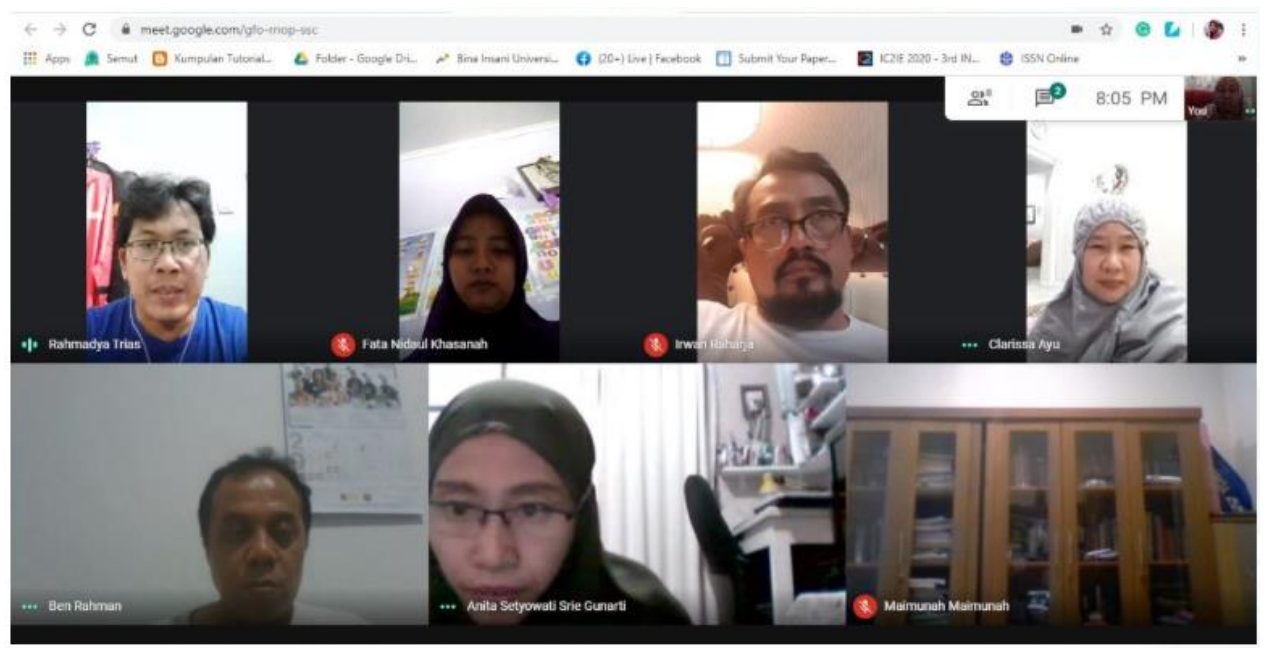

Sumber: Hasil Pelaksanaan (2020)

Gambar 1. Suasana Pertemuan Koordinasi Secara Online Dengan Menggunakan Aplikasi Buzme.In

Kegiatan pengabdian kepada masyarakat telah dilakukan pada Hari Sabtu, tanggal 6 Juni 2020 melaui media online workshop :https://meet.google.com. Meet.google dibuka tepat pada pukul 09.30 wib dengan melakukan konfirmasi ulang berupa regristasi peserta karena sebelumnya peserta sudah mendaftar melalui pendaftaran google form. Tepat pukul $10.00 \mathrm{wib}$ acara dengan tema "Optimalisasi Penggunaan Android untuk Peluang Usaha Bisnis Di masa Pandemi Covid '19 "ndimulai. Diawali dengan ucapan selamat datang dari ketua panitia dan sambutan dari ketua komite sekolah, dilanjutkan dengan penyampaian materi dari delapan pemateri dari perwakilan 5 Universitas di Indonesia. Kegiatan workshop diakhiri dengan pengisian kuesioner dan respon peserta terhadap keseluruhan acara, ditutup dengan foto booth online bersama. Kegiatan workshop selesai tepat pukul 12.30 wib. Metode pelaksanaan pengabdian masyarakat dilakukan meliputi 3 tahapan seperti disajikan dalam Gambar 2.

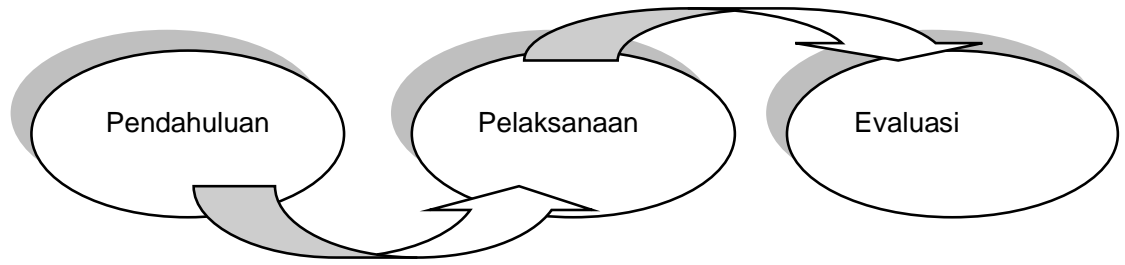

Sumber: Hasil Penelitian (2020)

Gambar 2. Metode pelaksanaan pengabdian masyarakat

Berdasarkan gambar 2, tahapan pelaksanaan pengabdian masyarakat meliputi:

\section{A. Tahap Pendahuluan}

Pada tahap ini, dilakukan analisis kebutuhan yang sangat diperlukan oleh masyarakat, terlebih dalam masa pandemik Covid '19. Ruang gerak dibatasi dengan Pembatasan 
Sosial Berskala Besar (PSBB) dan social distancing (jaga jarak) sehingga diperlukan media optimal yang dapat dijadikan sebagai peluang usaha untuk menambah penghasilan nyata bagi masyarakat. Berdasarkan diskusi di group Whatsapp Komite Sekolah SDIT Prestasi Cendekia, para anggota komite merasa perlu tutur ilmu cara-cara praktik pemanfaatan ANDROID sebagai salah satu medi dagang atau usaha. Selanjutnya kami bertemu dengan kepala sekolah dan ketua komite SDIT Prestasi Cendikia untuk melakukan wawancara dan diskusi tentang permasalahan yang sudah didiskusikan sebelumnya. Berdasarkan hal tersebut, disimpulkan bahwa para anggota komite memerlukan suatu kegiatan workshop atau pelatihan untuk menunjang kegiatan mereka selaku calon pelaku usaha (penambah income keluarga). Kegiatan offline sangat beresiko kami lakukan dimasa pandemi civod 19 ini, sehingga diusulkan kegiatan workshop secara online yang dikemas menarik, efektif dan efisien. Syukur Alhamdulillah, respon dari pihak komite dan sekolah cukup bagus, sehingga tersebarlah rencana kegiatan ini. Setelah itu, kami membuat group workshop kelas via WA untuk mengshare segala informasi dan menyebarkan flyer kegiatan, yang merupakan tahapan pendahuluan dari kegiatan ini. Selanjutnya dibuatkan form pendaftaran berupa url Google Form agar peserta dapat mendaftar workshop online dengan mudah dan cepat.

\section{B. Tahap Pelaksanaan}

Pelaksanaan pelatihan dilaksanakan via http://meet.google.com. Pelatihan dibuka dengan ucapan syukur kepada Allah SWT. Kemudian Ketua workshop memberikan beberapa kalimat sambutan kepada seluruh peserta pelatihan. Acara dibuka secara langsung oleh Ketua Komite SDIT Prestasi Cendekia dan dilanjutkan penyampaian materi oleh delapan orang pemateri dari 5 Universitas yang berbeda yaitu Universitas Islam 45 Bekasi, Universitas Bina Sarana Informatika, Universitas Bhayangkara Jakarta Raya, Universitas Muhammadiyah Magelang, dan Universitas Nasional). Materi yang disampaikan meliputi pemahaman fungsi ANDROID, HP sebagai media social informasi usaha, managemen dan cara meminimalkan resiko menggunakan penjualan online. Materi ini diharapkan mampu membangkitkan semangat peserta dalam memulai bisnis online tanpa takut akan kegagalan maupun kehilangan modal. Indikator keberhasilan pelaksanaan pengabdian kepada masyarakat dalam bentuk karya para peserta dalam memanfaatkan Andriod dengan membuat lapak pada aplikasi jualan online yang tersedia di play store atau website.

\section{Tahap Evaluasi}

Pada tahap evaluasi, para peserta dipersilahkan membuka https://menti.com dan mengisi langsung Kuesioner dan menuliskan respon atas penyelenggaraan workshop, mulai dari bobot materi, cara penyampaian materi, dan tanggapan terhadap keseluruhan kegiatan. Pada layar terlihat hasil kuesioner dan respon peserta secara realtime. Selanjutnya peserta mengirim hasil-hasil pelatihan melalui sharing Whatsapp group workshop. 
Seta Samsiana, Rahmadya Trias Handayanto, Anita Setyowati Srie Gunarti, Irwan Raharja,

Fata Nidaul Khasanah, Herlawati, Maimunah, Benrahman

Semua karya yang telah dibuat peserta pelatihan kemudian di unggah dalam group WA yang sudah dibuat sebelum pelatihan ini dilaksanakan.

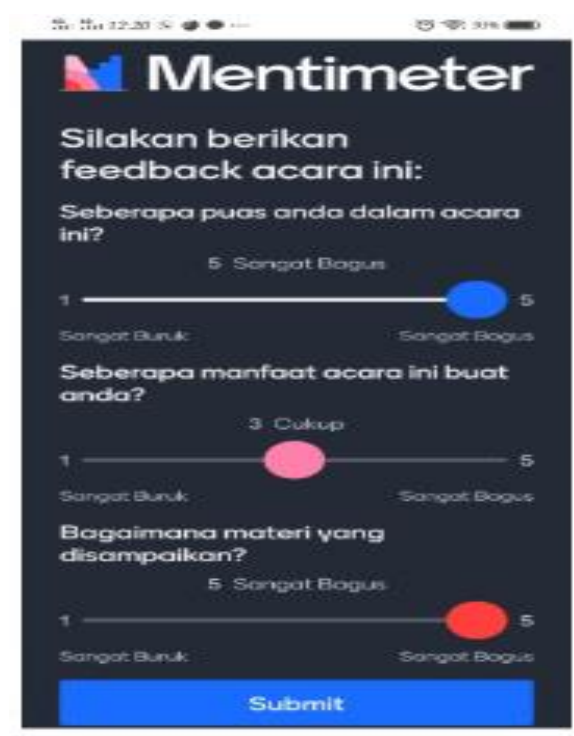

Sumber: http://menti.com (2020)

Gambar 3. Metode Evaluasi Kegiatan Dengan Mentimeter

\section{Hasil dan Pembahasan}

Kegiatan pengabdian kepada masyarakat ini diikuti oleh 53 ibu-ibu dari komite sekolah SDIT Prestasi Cendikia dengan waktu \pm 2 jam masa pelatihan. Pelatihan atau workshop dilakukan secara online melalui google meet. Gambar 4. merupakan Foto flyer dan link pendaftaran peserta workshop online menggunakan link google form dan hasilnya terlihat pada Gambar 5.
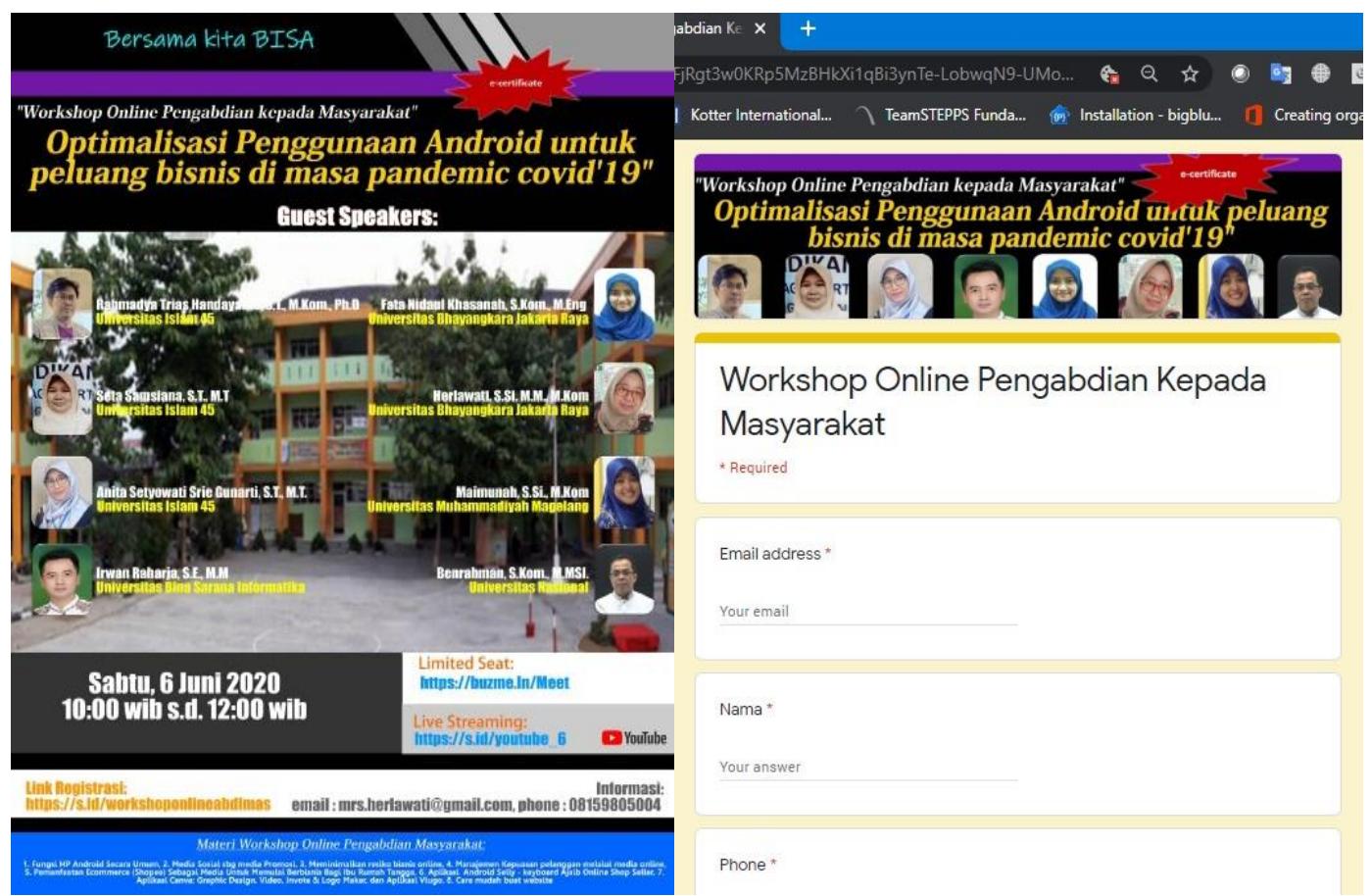

Sumber: Hasil Pelaksanaan (2020)

Gambar 4. Foto Flyer Dan Link Pendafatran Peserta Workshop 


\begin{tabular}{|c|c|c|c|c|c|c|}
\hline X Worksho & op Online Pengabdian Ke & epada Masyarakat Daftar. & † & Open with Google Sheets & $\mathbf{s} \mid \mathbf{v}$ & \\
\hline A & B & c & D & $\mathrm{E}$ & $\mathrm{F}$ & \\
\hline & Timestamp & Email Addrese & Nama & Phone & Alamat & Dari mana Ande \\
\hline 1 & 6/2/2020 7:51:46 & anitasegunarti@ymall.com & Anita Setyowati Srie Gunarti & 081323206332 & Kompleks Taman Sentosa B1 n & $n$ WA Group \\
\hline 2 & 6/2/2020 7:52:04 & 4 maimunah@ummgl.ac.id & Maimunah & +628157945559 & Magelang & WA Group \\
\hline 3 & 6/2/2020 8:09:55 & 5 mrsherlawat@gmail.com & Herlawati, S.SI., M.M., M.Kom & 08159805004 & Bekas & WA Group \\
\hline 4 & 6/2/2020 8:17:03 & khiarzana321@gmail.com & Wahyu Setiawati & $0812-3812-9000$ & Villa mutiara gading 2 blokV 2 & 2 WA Group \\
\hline 5 & 6/2/2020 8:17:26 & sasimuliat@@maill.com & Sasi mullati & 082112553367 & Bb12 № 9,perum. Damawang: & g: WA Group \\
\hline 6 & 6/2/2020 8:21:23 & Rhm121181@gmail.com & Rachma wati & 081387039673 & Mutiara gading 2 blok $\sqrt{ } 3$ no $\mathrm{k}$ & $k$ W.A Group \\
\hline 7 & 6/2/2020 8:23:15 & 5 naniherawati31@yahoo.co.id & Nani Herawati & 081285625359 & Babakan, Satria jaya RT 03 RU & W WA Group \\
\hline 8 & 6/2/2020 8:31:32 & 2 numhayatipermana@gmall.com & n Nurhayati & 081389531541 & Taman alamanda blokB1/63 & WA Group \\
\hline 9 & 6/2/2020 8:34:10 & emaykumi@gmail.com & Emay Mayseroh & $0813-18 B 1-6574$ & Karang Satria, Tambun Utara. I & IWA Group \\
\hline 10 & 6/2/2020 8:36:35 & 5 etty@nskcom & Eti supriatini & 082154941066 & Taman Alamanda bloke2 no 4 & 4 W.A Group \\
\hline 11 & 6/2/2020 8:37:19 & clustenw5@ymail.com & Eka Nurlaela (mam bunga) & 085775884802 & Cluster Alamanda blok W5 $\mathrm{no} 2$ & 2 WA Group \\
\hline 12 & 6/2/2020 8:40:35 & 5 laelasar178nda@mail.com & Ida Laelasari & 081806578308 & Damawangsa Residence Clustr & to W.A Group \\
\hline 13 & 6/2/2020 8:45:20 & rahmadya.trias@gmail.com & Rahmadya Trias Handayanto & 08159804756 & Vila Mutiara Gading 2 BlokV5/ & 3/ WA Group \\
\hline 14 & 6/2/2020 8:55:11 & ade.lwan2775@gmail.com & Nia Nurdiani & 08561728676 & Perum Bumi AnggrekBlokTU & WA Group \\
\hline 15 & 6/2/2020 9:20:45 & 5 k_pumama13@yahoo.com & Kumiati Pumamasari & 0811923093 & Cluster Alamanda W10 no. 4 & WA Group \\
\hline 16 & 6/2/2020 9:24:24 & 4 sn110982@gmail.com & Siti Nuraini & 085289891962 & Perumahan Damawangea resic & ic WA Group \\
\hline 17 & 6/2/2020 9:24:52 & 2 tribiandinur@ymail.com & Trí biyandinur & 087771937570 & Bintara 8- bekasi barat & WA Group \\
\hline 18 & 6/2/2020 9:39:20 & dwiyantiocta@ymail.com & Octa dy & 082258937520 & Jin P Yapen 17 no. $253 \mathrm{nt} 05 \mathrm{~m}$ & W WA Group \\
\hline 19 & 6/2/2020 9:45:23 & 3 liadamayanti.in@gmail.com & Lla Damayanti & 085775160556 & Damawangsa Residence, Clus & s W.A Group \\
\hline 20 & 6/2/2020 10:06:40 & o sus_ati@yahoo.com & SUSYATI & 081943658099 & Vila Mutiara Gading 2 BlokV 7 & 7 WA Group \\
\hline 21 & 6/2/2020 10:11:31 & I aidan.gc171017@gmail.com & Eka lus/awati & 082299586844 & Perum griya tambun & WA Group \\
\hline 22 & 6/2/2020 10:11:37 & 7 anisarahayu396@ymail.com & Pumanti & 089616987980 & Taman Alamanda blok 2 no & WA Group \\
\hline
\end{tabular}

Sumber: Hasil Pelaksanaan (2020)

Gambar 5. Hasil Pendaftaran Peserta Workshop

Sedangkan Gambar 6 menunjukan suasana pelatihan yang sedang berlangsung, terlihat pemateri dan peserta dan ada kolom chat di sebelah kanan. Dalam kolom chat peserta bisa mengajukan beberapa pertanyaan kepada pemateri. Pemateri yang sedang tidak presentasi bisa menanggapi pertanyaan langsung dari peserta menngunakan kolom chat tersebut.
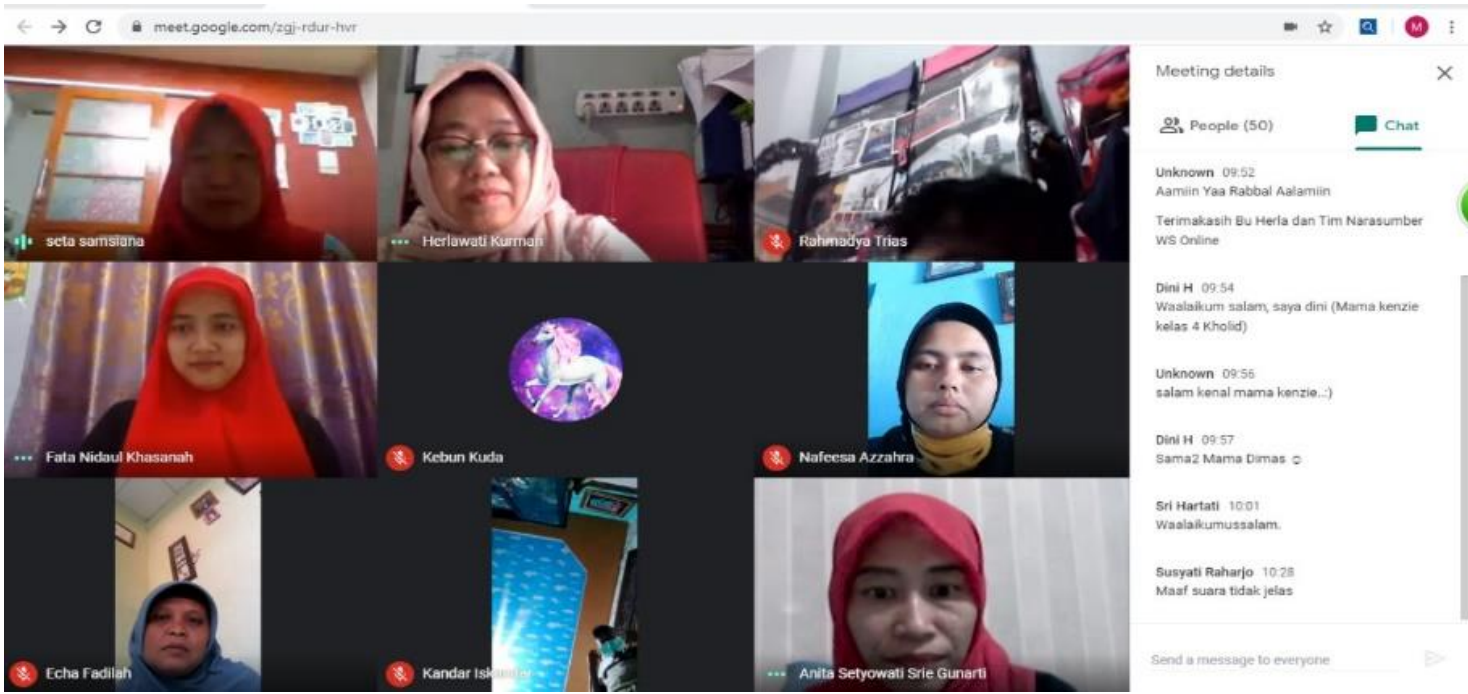

Sumber: Hasil Pelaksanaan (2020)

Gambar 6. Foto Kegiatan Worksop

Gambar 7 menunjukan tema materi yang disampaikan oleh pemateri dan tercantum menjadi cover belakang dalam sertfikat pemateri dan peserta workshop. 


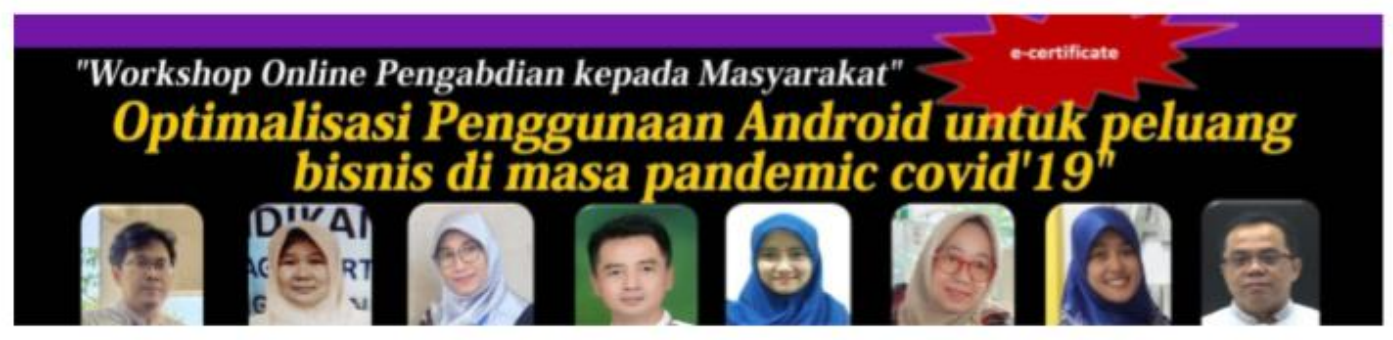

Sabtu, 6 Juni 2020, Pukul: $10.00-12.00$ WIB

\begin{tabular}{|c|l|l|l|}
\hline No & \multicolumn{1}{|c|}{ Nama } & \multicolumn{1}{|c|}{ Institusi } & \multicolumn{1}{|c|}{ Tema } \\
\hline 1 & $\begin{array}{l}\text { Rahmadya Trias Handayanto, S.T., } \\
\text { M.Kom, PhD }\end{array}$ & Universitas Islam 45 & Fungsi HP Android Secara Umum. \\
\hline 2 & Seta Samsiana, S.T., M.T & Universitas Islam 45 & Media Sosial sbg media Promosi \\
\hline 3 & Anita Setyowati Srie Gunarti, S.T., M.T. & Universitas Islam 45 & Meminimalkan resiko bianis online \\
\hline 4 & Irwan Raharja, S.E., M.M & Universitas Bina Sarana Informatika & Manajemen Kepuasan pelanggan melalui media online \\
\hline 5 & Fata Nidaul Khasanah, S.Kom., M.Eng & Universitas Bhayangkara Jakarta Raya & $\begin{array}{l}\text { Pemanfaatan Ecommerce (Shopee) Sebagai Media } \\
\text { Untuk Memulai Berbianis Bagi Ibu Rumah Tangaa }\end{array}$ \\
\hline 6 & Herlawati, S.Si. M.M, M.Kom & Universitas Bhayangkara Jakarta Raya & $\begin{array}{l}\text { Aplikasi Android Selly - keyboard Ajaib Online Shop } \\
\text { Seller. }\end{array}$ \\
\hline 7 & Maimunah, S.Si., M.Kom & Universitas Muhammadiyah Magelang & $\begin{array}{l}\text { Aplikasi Canva. Graphic Design, Video, Invote \& Logo } \\
\text { Maker dan Aplikasi VlogU. }\end{array}$ \\
\hline 8 & Benrahman, S.Kom., M.MSI & Universitas Nasional & Cara mudah membuat Website \\
\hline
\end{tabular}

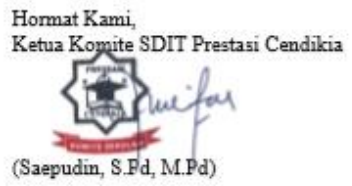

Sumber: Hasil Pelaksanaan (2020)

Gambar 7. Materi Yang Disampaikan Pada Kegiatan Workshop

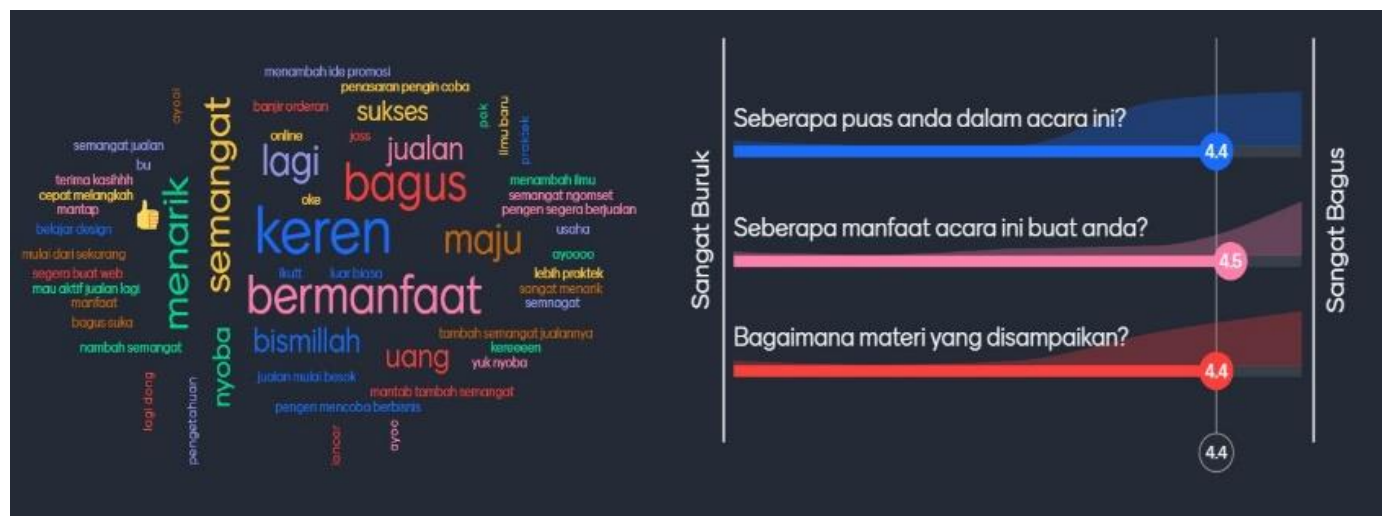

Sumber: Hasil Pelaksanaan (2020)

Gambar 8. Respon Dan Hasil Kuesioner Berupa Penilaian Realtime Dari Peserta

Gambar 8 merupakan hasil feedback peserta setelah pelaksanaan kegiatan workshop berlangsung. Pengambilan hasil feedback dilaksanakan di akhir acara menggunakan sebuah aplikasi menggunakan Handphone Android yaitu mentimeter dengan url-nya http://menti.com. Panitia menyiapkan pertanyaannya dan sebuah kode yang harus dimasukan oleh peserta yang sesudah membuka url tadi. Kemudian peserta mengisikan pendapatnya tentang acara kegiatan yang sudah dilaksanakan tadi di handphonenya. Akhirnya muncullah hasil seluruh pendapat peserta itu di layer monitor panitia dan seluruh peserta bisa melihat hasil feedback terhadap kegiatan tersebut terlihat pada Gambar 9 dan Gambar 10. 


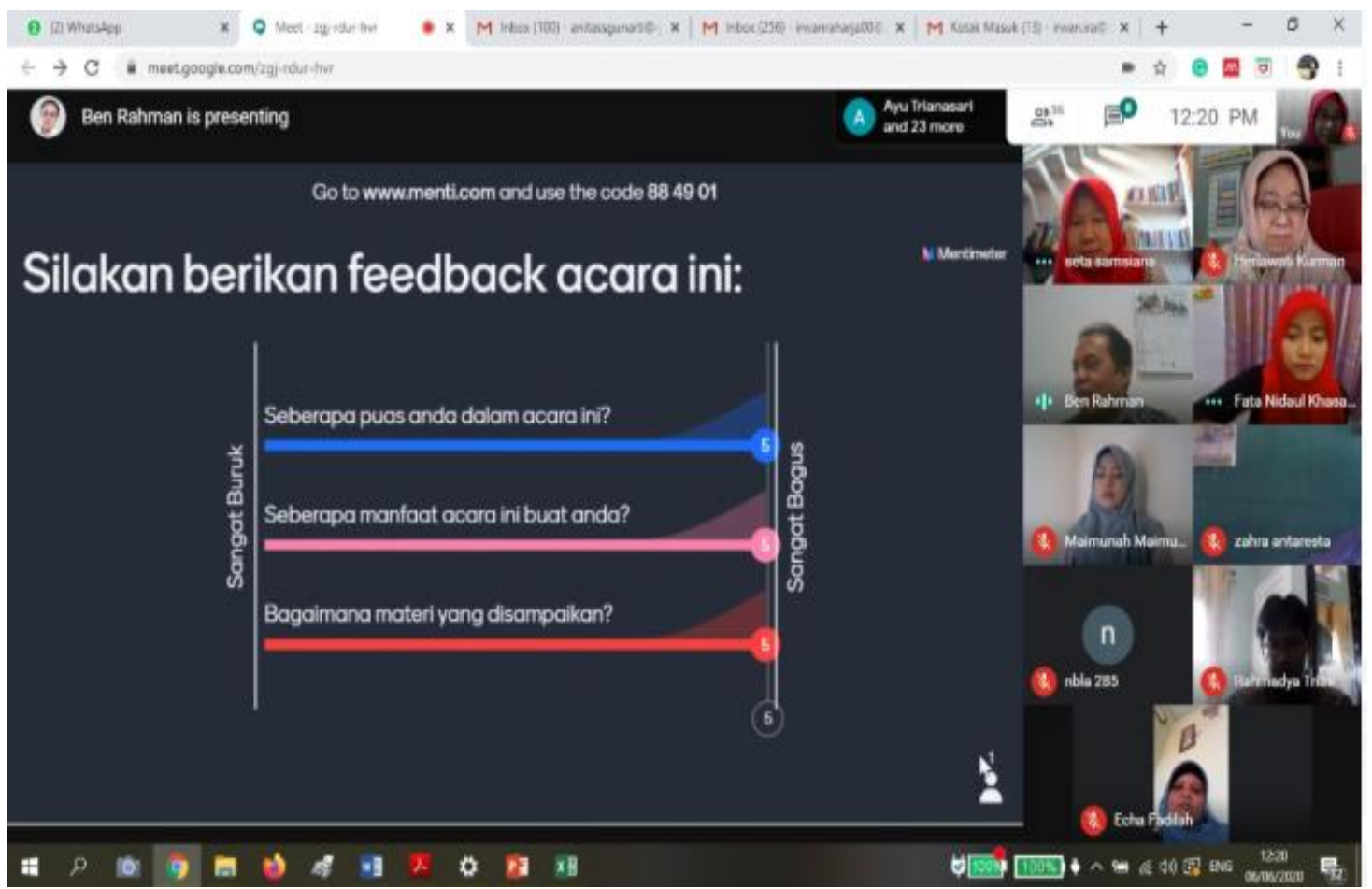

Sumber: Hasil Pelaksanaan (2020)

Gambar 9. Suasana Ketika Pengambilan Respon Dan Hasil Kuesioner Berupa Penilaian Realtime Dari Peserta (1)

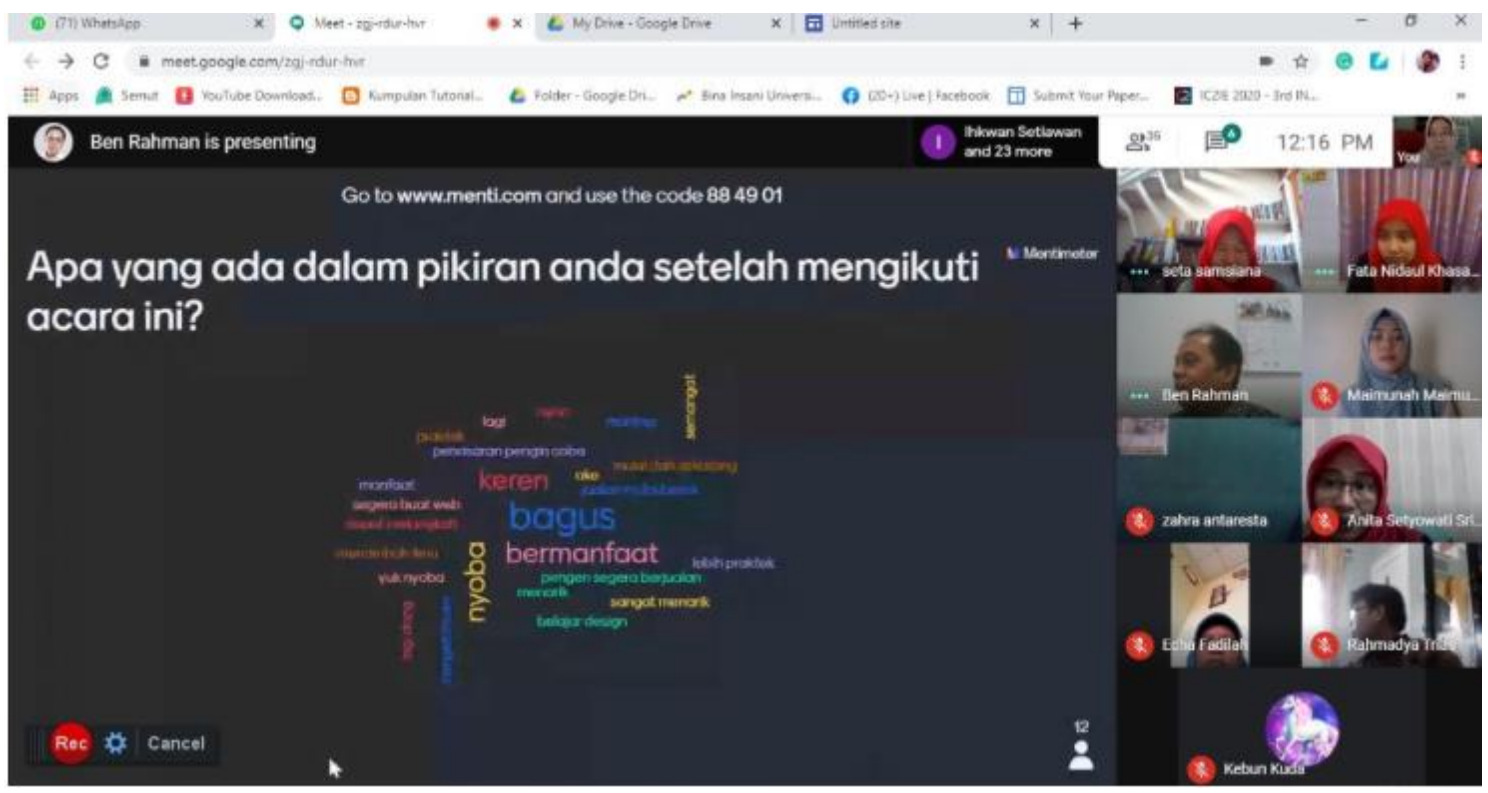

Sumber: Hasil Pelaksanaan (2020)

Gambar 10. Suasana Ketika Pengambilan Respon Dan Hasil Kuesioner Berupa Penilaian Realtime Dari Peserta (2)

\section{Analisis kondisi Peserta:}

a) Sebelum dilakukan Pengabdian Kepada Masyarakat

Para anggota komite SDIT Prestasi Cendikia yang merupakan peserta pelatihan, belum memahami fungsi HP Android secara luas, salah satunya sebagai media sosial penjualan, promosi maupun aplikasi-aplikasi lainnya. Mereka faham fungsi HP ANDROID sebagai sarana 
Seta Samsiana, Rahmadya Trias Handayanto, Anita Setyowati Srie Gunarti, Irwan Raharja,

Fata Nidaul Khasanah, Herlawati, Maimunah, Benrahman

komunikasi tetapi informasi dengan aplikasi penunjang belum dipahami. Produk penjualan baik barang maupun jasa sudah sebagian peserta miliki hanya usaha yang dilakukan sebagian besar masih offline saja.

b) Sesudah dilakukan pengabdian Masyarakat

Setelah dilakukan workshop, peserta dari komite sekolah SDIT Prestasi Cendekia lebih memahami dan menumbuhkan semangat baru bagi peserta untuk memulai usaha dengan pengetahuan yang lebih bagus.

c) Luaran Kegiatan Pengabdian Masyarakat

Luaran kegiatan ini adalah peserta pelatihan mampu menggunakan dan mengoptimalkan HP Android sebagai sarana usaha. Peserta paham fungsi HP Android sebagai sarana penjualan, promosi, managemen dan e-commerce.

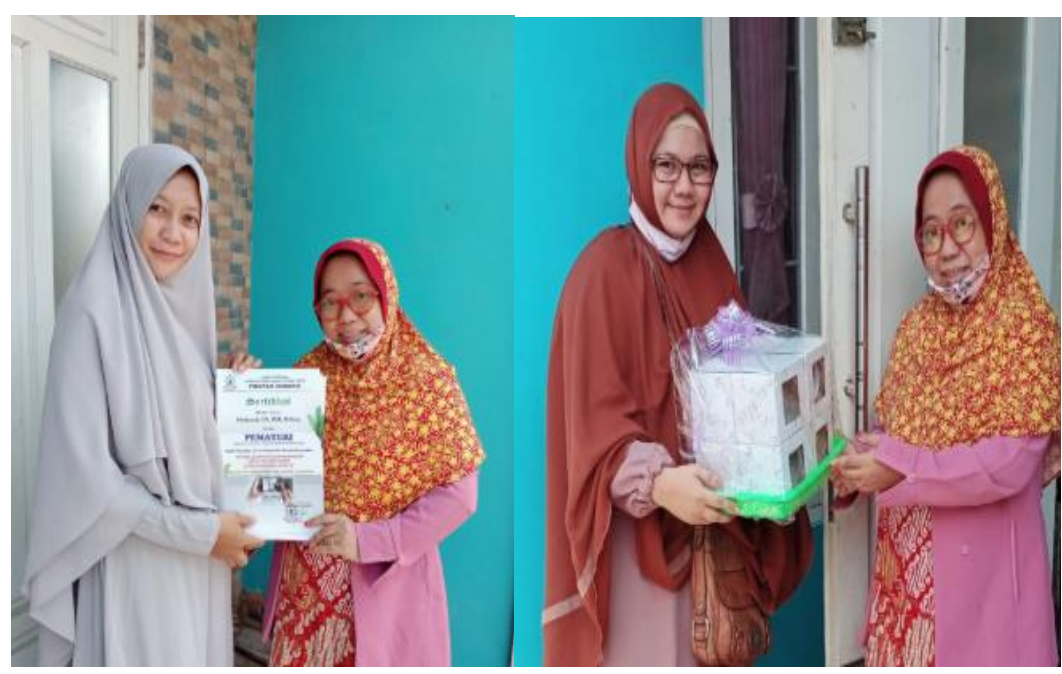

Sumber: Hasil Pelaksanaan (2020)

Gambar 11. Penyerahan sertifikat pemateri dan salah satu produk yang dibuat untuk dijadikan contoh peluang bisnis dari Komite Sekolah
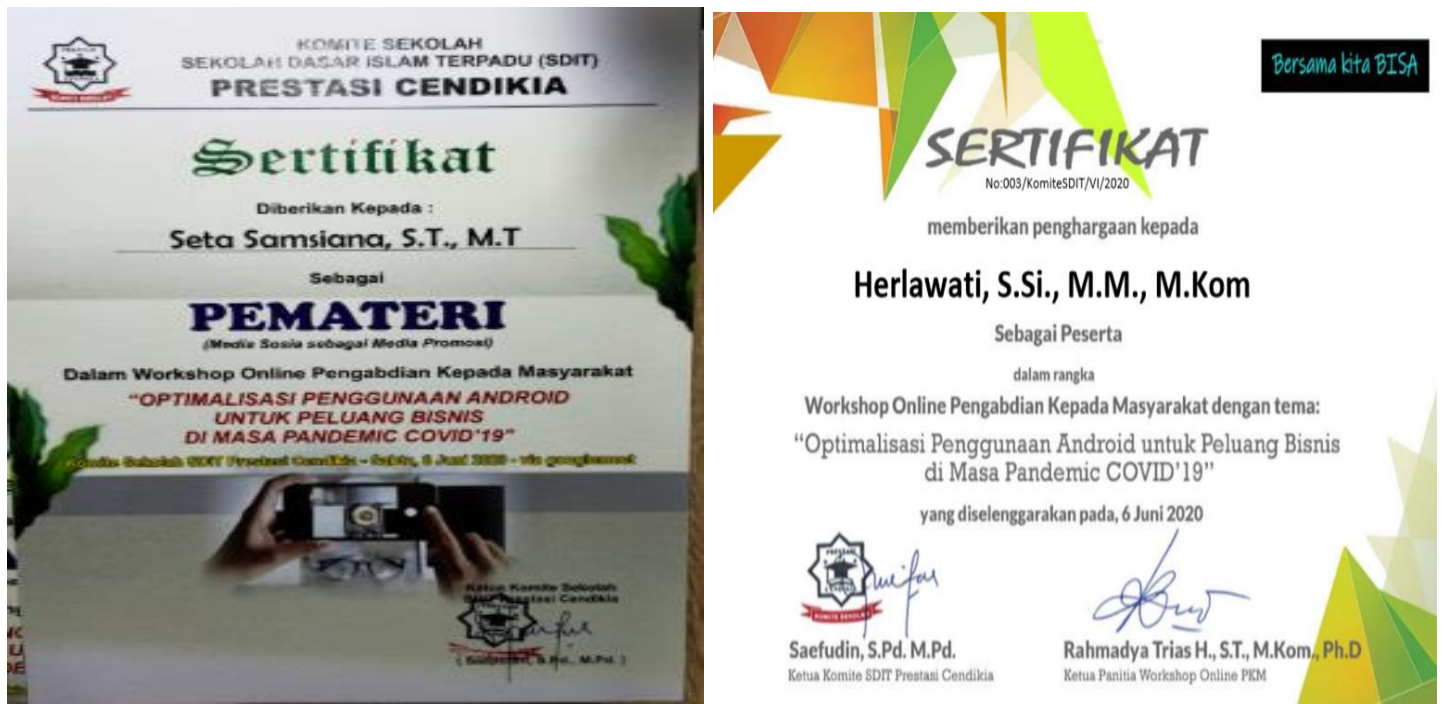

Sumber: Hasil Pelaksanaan (2020)

Gambar 12. Contoh Desain Sertifikat Pemateri dan Peserta 

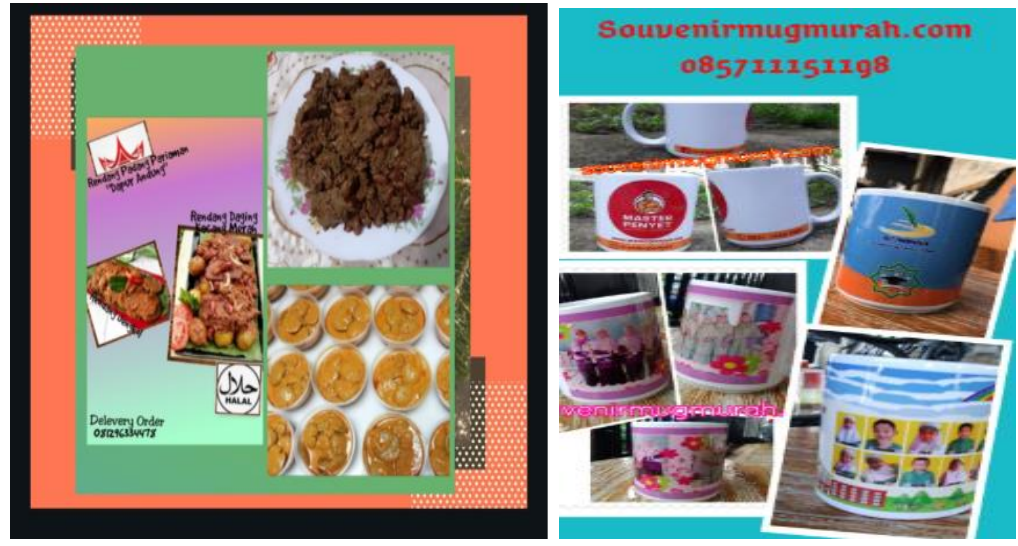

Sumber: Hasil Pelaksanaan (2020)

Gambar 13. Contoh Hasil Desain Peserta Workshop Online

Untuk memacu kegiatan online pengabdian kepada masyarakat di masa pandemic, kami menginformasikan kegiatan ini di salah satu media masa nasional. Semoga bisa menginspirasi kegiatan-kegiatan yang serupa untuk membantu masyarakat.

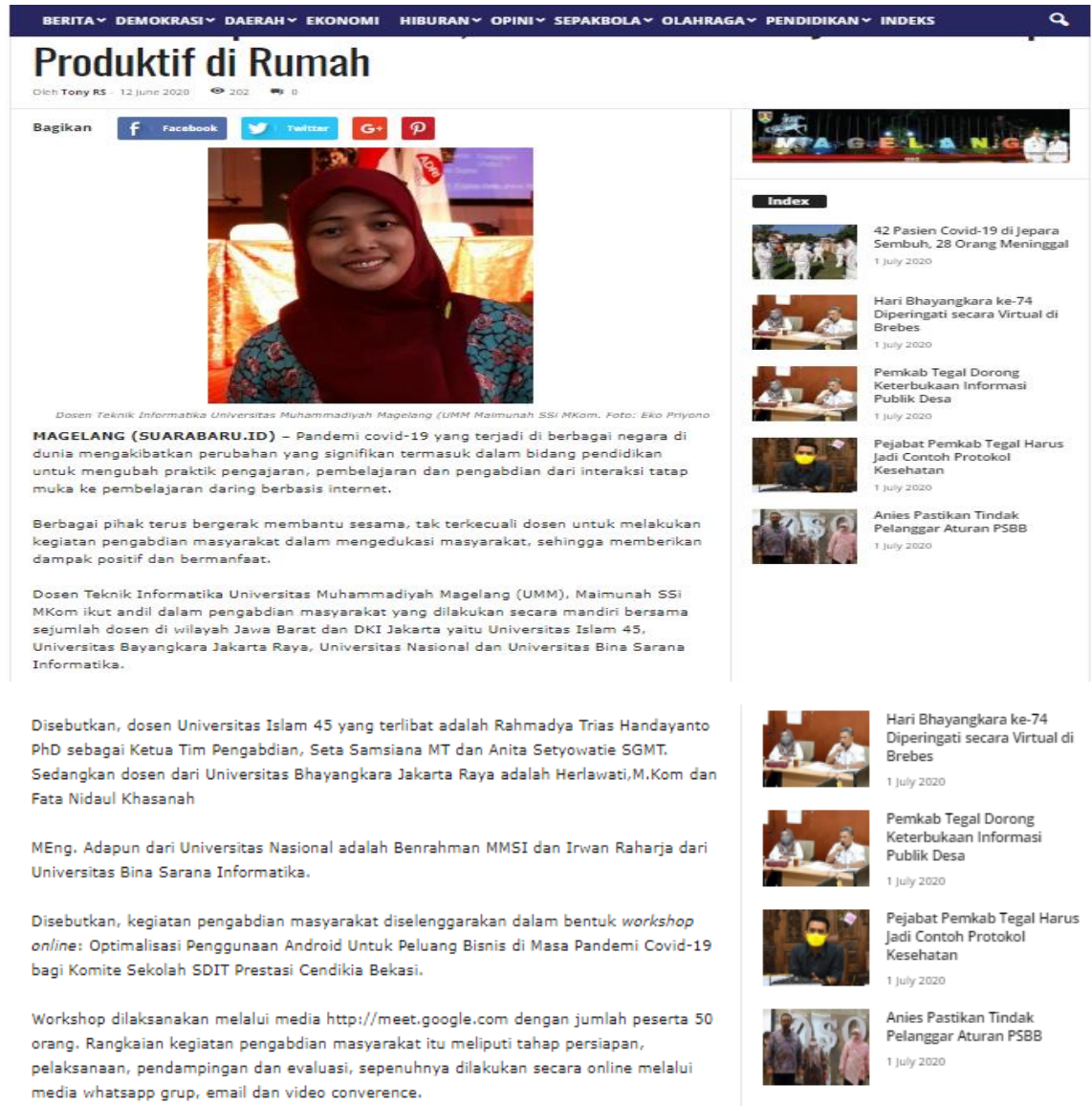

Sumber: http://suarabaru.id/2020/06/12/peduli-dampak-covid-19-dosen-edukasi-masyarakat-tetap-produktif-di-rumah/ Gambar 14. Berita Tentang Kegiatan Workshop Di Salah Satu Media Masa Nasional.

\section{Kesimpulan}

Berdasarkan hasil kegiatan pengabdian kepada masyarkaat yang telah dilakukan, dapat disimpulkan bahwa para peserta sangat respon atas penyelenggaraan workhop ini. Hal ini terbukti dari banyaknya peserta yang mendaftar melalui google form. Android sebagai media 
Seta Samsiana, Rahmadya Trias Handayanto, Anita Setyowati Srie Gunarti, Irwan Raharja,

Fata Nidaul Khasanah, Herlawati, Maimunah, Benrahman

sosial dengan 177 juta pengguna menjadi peluang usaha yang cukup menjanjikan. melalui workshop "Optimalisasi Penggunaan Android untuk Peluang Usaha Bisnis Di masa Pandemik Covid'19 ", peserta memahami dan mampu meningkatkan penguasaan Android dengan baik, peserta semakin bersemangat untuk berbisnis dengan menggunakan Android.

\section{Ucapan Terima Kasih}

Syukur Alhamdulillah kami panjatkan kepada Allah SWT atas rahmat dan hidayahNya kegiatan pengabdian pada masyarakat ini terslenggara dengan baik dan lancar. Tak lupa kami mengucapkan banyak terima kasih kepada semua pihak yang ikut terlibat dalam kegiatan pengabdian kepada masyarakat ini baik langsung maupun tidak langsung. Kepada Kepala Sekolah SDIT Prestasi Cendikia, Kepada Ketua Komite Sekolah SDIT Prestasi Cendikia yang telah memberikan kesempatan kami untuk berbagi ilmu pengetahuan dan teknologi. Selanjutnya kepada tim pengabdian kepada masyarakat atas kerjasama yang terjalin untuk kesuksesan kegiatan ini. Semoga Allah SWT senantiasa memberikan keberkahan atas kegiatan ini dan memberikan pemahaman atas ilmu yang barokah. Amin ya rabbalallamin.

\section{Daftar Pustaka}

Baskoro, M. L., \& Maulidian, M. (2019). Pelatihan Instagram Marketing Untuk Tenant Inkubator Bisnis Trilogi. Jurdimas, 2(1), 1-26.

Febrilia, I., Nasution, H., \& Handarini, D. (2017). Pelatihan Penggunaan Jejaring Sosial Instagram Dalam Memasarkan Barang Pada lbu-lbu Pkk Di Kelurahan Rawamangun Jakarta Timur. Sarwahita, 14(2), 108-113.

Purwati, Y., \& Perdanawanti, L. (2019). Pelatihan Desain Menggunakan Aplikasi Canva Untuk Anggota Komunitas Ibu Profesional Banyumas Raya. Jpmm (Jurnal Pengabdian Mitra Masyarakat), 1(1), 42-51.

Rachman, A. N., \& Ramdani, C. M. S. (2016). IBM Pelatihan Pemanfaatan E-Commerce Sebagai Media Pemasaran Global Untuk Peningkatan Penjualan Produk Kelom Geulis (Studi Kasus: Ukm Kelom Geulis Tamansari Tasikmalaya). Jurnal Pengabdian Siliwangi, 2(1).

Rifai, Z., \& Oktaviana, L. D. (2018). Pelatihan Aplikasi Teknis Online Marketplace Pada Sentra Umkm Banyumas "Pratistha Harsa" Untuk Pemasaran Produk Secara Online. Jurnal Abdimas BSI Jurnal Pengabdian Kepada Masyarakat, 1(3).

Suyanto, M. (2003). Strategi Periklanan Pada E-Commerce Perusahaan Top Dunia. Andi Offset.

Werdani, R. E., Kurniawati, N. I., Sukoco, J. B., Windriya, A., \& Iskandar, D. (2020). Pelatihan Pemasaran Produk Homemade Melalui Sosial Media. Jppm (Jurnal Pengabdian Dan Pemberdayaan Masyarakat), 4(1), 1-5. 